\title{
Researcher of the Year 2020 To Recognize the Significant Efforts for COVID-19
}

\author{
Ashutosh Tiwari* iD \\ Secretary General, International Association of Advanced Materials, Gammalkilsvägen 18, Ulrika 590 53, Sweden \\ *Corresponding author: E-mail: secretarygeneral@iaamonline.org; Tel: (+46) 1313-2424 \\ DOI: $10.5185 /$ amlett.2020.121579
}

In this pandemic year, International Association of Advanced Materials (IAAM) has endeavoured to recognize the best efforts of researchers for their overall efforts to combat COVID-19 in order to select the recipient of the prestigious title of 'Researcher of the Year'. As an international organization actively working in the scientific community, International Association of Advanced Materials is quite concerned in this time of COVID-19 outbreak. The organization has prioritized all its operations to make valuable contributions to the advanced materials community in this time of need. IAAM believes that the adaptation of advanced technologies and their logical integration according to contemporary healthcare measures could be a smart strategy for COVID-19 management.

The title of 'Researcher of the Year' is the highest award that the International Association of Advanced Materials honours scientists and researchers with. Every year, the association announces the 'Researcher of the Year' with a lot of pride to recognize the hard work and path-breaking efforts of a scientist towards the advancement of materials to global excellence. In the last decade, the title of 'Researcher of the Year' conferred by IAAM has become one of the highest regarded honours that any researcher or scientist working in an interdisciplinary scientific field can have the pleasure to receive.

The title of 'Researcher of the Year' is the top-most award conferred upon researchers by IAAM. Therefore, the association is quite selective regarding it. This highly prestigious honour is conferred upon a researcher or scientist who has been a leader in an important interdisciplinary field of science. All over the globe, any scientist or researcher who has made some really outstanding contributions to the world of science with their research and results along with making efforts towards the dissemination of scientific education, promotion of materials science research, and its application is considered eligible for this honour. The achievements and contributions during a set period is considered for the selection. Professor Prasad KDV Yarlagadda is recognised with Researcher of the Year 2020 due to his outstanding contribution in the advancement of anti-viral and antibacterial surfaces in including COVID-19.

\section{Contribution to anti-viral and anti-bacterial research}

Prof. Prasad KDV Yarlagadda is leading a team of mid-career and young researchers for applications in several areas of healthcare. The Smart Structures and BioInterface Group (SSBIG) at Queensland University of Technology (QUT), Australia, is headed by Prof. Yarlagadda. Creating micro and nanoscale structures with multi-bio-functional properties is one of the focus areas of
SSBIG. Over the last decade, Prof. Yarlagadda has been largely involved in antipathogenic surfaces, 3D metal printing technology, statistical modelling, simulation, microfluidic devices, coatings and investigating atherosclerotic plaque tissue for various biomedical applications. For all these projects, SSBIG has been working in collaboration with a number of national and international collaborators such as Royal Brisbane and Women's Hospital, Herston Biofabrication Institute (Metro North, Brisbane), Stryker, Indian Institute of Science, India, and others. A brief description of some of his major projects has been outlined.

\section{Antipathogenic surfaces that kill bacteria and viruses}

Using a range of advanced fabrication techniques, nanostructured surfaces have been manufactured at SSBIG, QUT, which have shown excellent bactericidal as well as antiviral characteristics. In this area, there are several subprojects that have been continuing with in-depth scientific advances.

Nano-pillared titanium [1-4] substrates have been fabricated using hydrothermal processing. The surface architecture has been selectively modulated using the fabrication processing parameters such as temperature, reaction time, and reactant molarity. The nano-pillared substrates were characterized using advanced surface characterization studies such as scanning electron microscopy, nanoindentation, FTIR, XRD, and others. The bacterial attachment investigation was also performed which showed excellent bactericidal behaviour against the notorious coccoid Staphylococcus aureus and Pseudomonas aeruginosa. The surfaces also promoted the attachment of osteoblast cell lines. A statistical model was established that correlate the fabrication processing parameters with the bactericidal behavior. The antiviral studies of hydrothermally processed titanium substrates are currently undergoing. These nano-pillared titanium 


\section{Advanced Materials Letters www.vbripress.com/aml}

surfaces have excellent applications in biomedical implant and surgical device sector.

Medically relevant nanostructured Aluminum alloys $[\mathbf{5 , 6}]$ have been wet-etched in strong bases that create randomly oriented nanoscale features on the substrates. The substrates have been shown to kill a range of bacteria efficiently. This fabrication method can be easily scaled up and is quite economical compared to other fabrication methods. Recently, the nanostructured Al surfaces were shown to be effective against rhinovirus and respiratory syncytial virus as well. These nanostructures were also shown to have excellent durability. Currently, the substrates are being tested against SARS-CoV-2. These substrates have scope to be installed in hospital environments to tackle hospital acquired infections.

Taking inspiration form cicada wings, nanopatterned titanium pillars $[\mathbf{1 , 7 ]}$ have been successfully fabricated using electron beam lithography (EBL). In this project, a variety of nanopatterned geometries were fabricated based on the three species of cicadas having different wing nanopillar geometries. The nanopatterned substrates were found to be both bactericidal as well as cytocompatibility. Using the EBL method, a highly controlled nanoscale geometry can be designed.

Currently, they are also looking at a number of other industrially relevant and scalable techniques to inactivate bacteria and viruses which include plasma treatment, naturally derived coatings, antibiotic coatings or surface functionalization, and electrochemical etching.

\section{Micro-nanofluidic platform for studying bacteria in flow}

A stainless-steel microfluidic platform has been designed and fabricated with sandwiched nanostructured substrates in a channel to investigate the behavior of bacterial cells under varying shears, flow rates, nanopillar architecture. This is particularly important to study the behavior of bacterial infections in flow such as bloodstream infections, urinary catheter infection, etc.

\section{Bacterial killing and Virus deactivation mechanisms on nanopillar surfaces}

This is a paradigm-shifting project which will reveal the wonders of bacterial killing mechanism and killing of number of respiratory viruses including SARS-CoV-2 virus on the nanopillars [8-11]. It is currently being carried out using a combination of sophisticated computer aided modelling and simulation backed up with experimental verification. The project is on the verge of providing a breakthrough in the current understanding of bacterial death through physical disruption. Till now, SSBIG has studied the non-linear, non-developable deformation of the cell envelope on nanopatterned arrays using threedimensional finite element analysis. The computational modelling has demonstrated the critical action site of nanostructured arrays and their enhancement through optimized geometric design. The findings from this work are being used to guide the design and fabrication of their nanostructured surfaces. This synergistic relationship between modelling and fabrication is one that SSBIG seeks to emphasize in their future research in killing number of other bacteria and viruses with different nano-textured materials as well.

\section{Biography and research journey}

Prof. Prasad KDV Yarlagadda is an internationally recognized expert in the fields of digital manufacturing and their applications for automotive, aerospace, tissue engineering, permanent scaffold production for orthopedic applications, fracture fixation methods. During the last 35 years, he has worked in university maintaining strong collaborations with the industry for working towards solving real-world problems. Prof. Yarlagadda's dedicated service has led to advancement of manufacturing engineering education, which has further contributed to global engineering education and other higher education sectors. His research contribution is reflected in his popularity and research findings which have a very significant impact in the field of manufacturing and its applicability to various disciplines.

Prof. Yarlagadda was born in the year 1961 in Vijayawada, India. He was first person in his family who completed high school studies and went to university for higher education. As his parents are from business community with minimum educational skills, he always needed to depend on others around him for advice on his future education. Prof. Yarlagadda gratefully acknowledges three people who had long lasting influence on his education. They are Late Mr. Tummala Seshagiri Rao (Science Lecturer) during his primary education and the other one is Late G. Rama Krishna Raju, who is the father of his good friend Mr. G.S.N Raju (Chitti Babu). Both provided invaluable guidance and support in planning for his higher education. Once he started his higher education, there is another person, who had profound influence on Prof. Yarlagadda's academic journey and research success. His name is Dr. D. Radha Prasada Raju, who mentored, guided, and supported Prof. Yarlagadda throughout his academic career. Prof. Yarlagadda often mentions these three people who helped him in establishing strong foundation for his academic landscape. Prof. Prasad always believed that education is the primary and an important aspect of anyone's future and it helps people to change their future, culture, life style, and more importantly, it is an important asset which stays with us forever, which can neither be lost nor stolen. Knowing the value of education, he made heartful effort to support all his next generation family members and made sure all of them are educated to highest levels (Fig. 1(A)). In addition to helping his own family members, Prof. Yarlagadda has helped number of people from remote communities of Sri Lanka and the Himalayan community in India to go to college and receive higher education through his sponsorship and support schemes. Prof. Yarlagadda successfully completed supervision of 51 HDR students and is currently supervising $16 \mathrm{PhD}$ students and his current team is shown in the Fig. 1(B). 


\section{Advanced Materials Letters www.vbripress.com/aml}
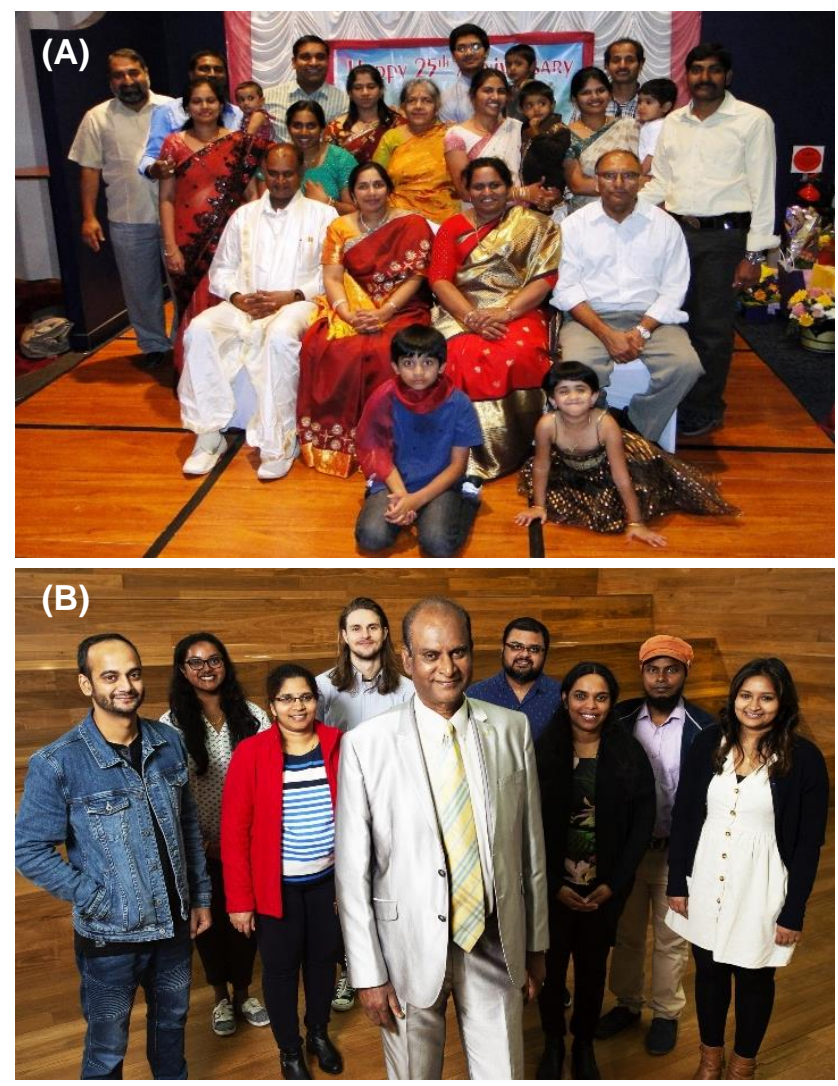

Fig. 1. (A) Prof. Prasad, along with his wife Ragamayi, daughter Tejasri, and extended family in Australia (Photo taken in remembrance and of 25th wedding anniversary on 7th December 2011); and (B) Prof. Prasad Yarlagadda along with his research team: (Starting from left): Dr. Jafar Hasan, Ms. Arpana Gopi Panicker, Dr. Phani Kumari Paritala, Mr. Amar Velic, Mr. Amal Senevirathne, Dr. Asha Mathew, Dr. Majedul Islam, and Dr. Alka Jaggessar.

Prof. Yarlagadda studied mechanical engineering at Nagarjuna University (1983), Vijayawada, India. After his bachelor's degree, Prof. Yarlagadda worked as a maintenance engineer in Lakshmi Engineering Works, Vijayawada, India (Sep 1983-July 1984). In the year 1986, he obtained a Master of Engineering degree specialised in Production Engineering from Bharathiar University, Coimbatore, India. During his $\mathrm{PhD}$, he worked as a Research Scholar (IIT Bombay) and Lecturer (V.R.S Engg. College, Vijayawada, India). In the year 1992, he obtained his $\mathrm{PhD}$ in Production Engineering from Indian Institute of Technology, Bombay, India. After completing his doctorate, Prof. Yarlagadda moved to City University of Hong Kong, Hong Kong, to conduct his post-doctoral research and worked as a visiting lecturer (Dec 1992-March 1995) (Fig. 2(A)). In 1995, he joined PNG University of Technology, Papua New Guinea, as a Lecturer. One year later, he moved to Queensland University of Technology (QUT), Australia, and served as a Lecturer in the School of Mechanical, Manufacturing \& Medical Engg. This decision would not have been easier, as he had received six appointments to choose from, from a number of countries, including one of the top universities in Australia. Prof. Prasad chose QUT, it being a young and dynamic university and ranked as best teaching university in Australia during that time. During our conversations, Prof. Prasad mentioned that he has always been happy about this decision to join QUT by declining an offer from one of the universities which ranked Top 25 in the world. He is enjoying his career and his engagement with his profession over the past 25 years in QUT.

Prof. Yarlagadda has served in various positions at QUT in the last 25 years. He started as a lecturer (January 1996 - July 1998), then became the director Manufacturing Systems Engineering Research Concentration and a senior lecturer (August 1998 - July 2003). In August 2003, he was promoted as an Associate Professor and Program Leader (Product Design \& Manufacturing) (Fig. 2(B)). Later in Jul 2004, he became an Associate Director, (Centre for Built Environment \& Engineering Research) and Asst. Dean (Research), Faculty of Built Environment and Engineering at QUT. In Aug 2005, he started to serve as Professor \& Director Smart Systems Research at QUT. From Jan 2006, he served as Head, Discipline of Mechanical, Manufacturing, and Mechatronics Engineering, Faculty of Built Environment and Engineering. Since July 2009, he has been a Project Director, Airports of the Future \& Professor in Smart Systems. The airports of the future is a multi-disciplinary international collaborative research project exploring the complexity of modern airports and addressing conflicts between aviation security and the passenger experience [12]. This project is drawn upon diverse strengths through a university-industry-government partnership to develop tools to manage airport effectiveness and balance conflicting security, economic and passenger-driven pressures. As a Project Director, he represented research team in the Advisory Committee, which comprised of executives and senior managers whose expertise and experience enabled them to offer informed advice on the strategic and timely development of the substantive areas of the research project. He is also responsible for managing the total project budget $(\$ 10 \mathrm{M})$, research deliverables and outputs, interaction with 13 CIs, 30 other project team members, and 32 industry partners consisting of various federal and border control agencies such as Australian Customs, Federal Police, Department of Immigration, Australian Quarantine services, Department of Infrastructure, Office of Transport Security, various Australian airports, and airline partners such as Qantas and Emirates.

Moreover, he had several distinguished appointments in various universities in India, China, and Australia. Prof. Yarlagadda also served as coordinator of CEED (Cooperative Education for Enterprise Development) projects. Through this, he identified the right personnel for the real-world problems faced by industries in Australia, Singapore, Malaysia, and South Korea. He is the Editor in Chief and, Deputy Editor-in-chief of 04 International Journals, and also editorial board member of 18 ISI listed Journals. He is a fellow and member of many professional organisations such as Engineers Australia, the Institution of 


\section{Advanced Materials Letters www.vbripress.com/aml}

Engineers (India), World Academy of Manufacturing and Materials Engineering, American Society of Mechanical Engineers, Society of Manufacturing Engineers, Institution of Mechanical Engineers, UK; Australia New Zealand Solar Energy Society, Australia and Founding member of Manufacturing Society of Australia), Institution of Engineers, Australia, and more recently, he became the Fellow of International Association of Advanced Materials. He was recently elected as Principal Fellow of Higher Education Academy, UK, which is highest recognition one can receive for contribution to higher education worldwide. In his research career, Prof. Yarlagadda has published 500+ articles in various international refereed journals and conference proceedings and has been successful in attracting research funding of the order $\$ 16.5$ $\mathrm{M}$ from various funding agencies and industries. He has delivered 50 keynote lectures in various universities and international conferences around the world. His recent Keynote lecture was presented in the Global Congress on Manufacturing and Management 2016 on Digital Manufacturing and Future of Medical Devices in Zhengzhou, China (Fig. 2(C)).
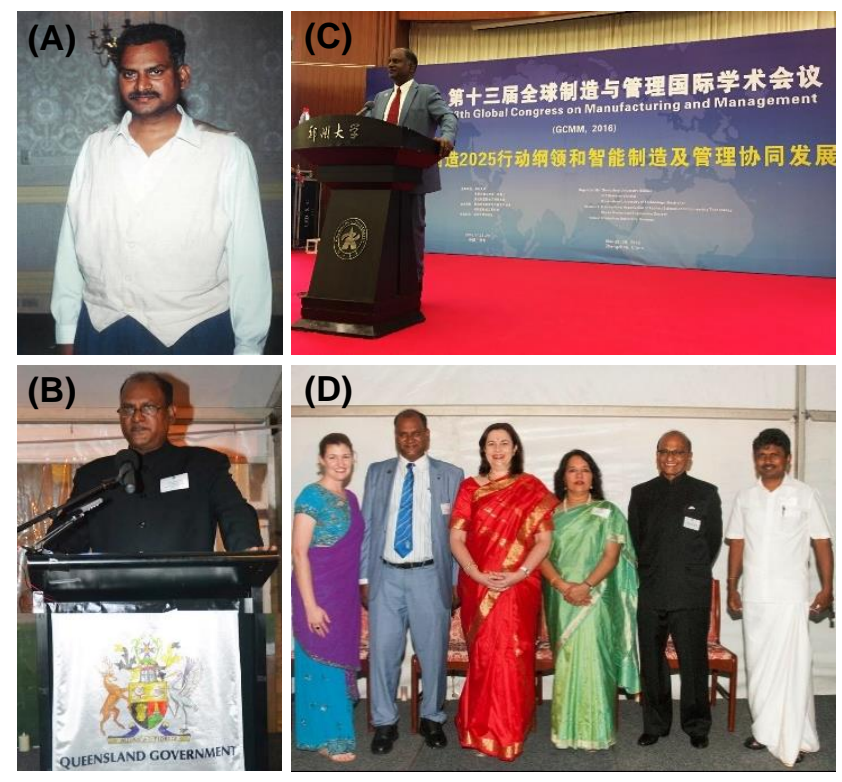

Fig. 2. (A) Prof. Yarlagadda during his Post-Doctoral Fellowship time at City University of Hong Kong; (B) Prof. Yarlagadda, President, Federation of Indian Communities of Queensland giving a talk in Queensland Parliament on Queensland India relationship and enhancing partnership between Queensland government and India during November 2014; (C) Prof. Yarlagadda Giving a keynote Lecture on Digital Manufacturing and Future of Medical Devices During GCMM 2016 in Zhengzhou, China; (D) FICQ Indian community Diwali celebration with Queensland Premier Hon. Anastacia Palaszczuk, Multicultural Minister Hon Shannon Fentiman and other dignitaries.

\section{Leadership in teaching and education}

As a teacher of manufacturing engineering discipline, Prof. Yarlagadda has provided guidance and leadership through teaching practice, innovative teaching methods, and workplace learning practices. $\mathrm{He}$ has been actively involved in various teaching development activities in
South East Asia and Pacific region as the Editor, AEESEAP Journal of Engineering Education, and through hosting Engineering Management Educators Conferences. He has successfully implemented the innovative teaching methods and promoted teaching improvement. As a recognition to his teaching innovation, he received Innovation in BEE Education Award (2002). Prof. Yarlagadda also developed three new innovative units and has taken leadership role in inter-faculty CUTSD funded project on RobSoccer. He developed Infomechatronics Engineering as an integrative experience for students. Infomechatronics is a multidisplayer discipline and different from traditional engineering disciplines. He contends that through this course, students get well prepared to enter critical, ethical, and professional engineering practice. Through this course he promoted student learning through problem/project based learning approaches such as (a) integration of project based learning approach through a multi-disciplinary unit, (b) problem based learning experience through interdisciplinary teamwork and (c) Promoting workplace readiness through targeted project work. The outcomes of the above-mentioned activities have been presented and published in various conferences and international journals on engineering education.

Prof. Yarlagadda led a new state-of-the-art project: "A new supervision framework for Non-English Speaking Background (NESB) Higher Degrees Research (HDR) Students" to develop a research supervision framework that will enhance completion rates for non-English speaking background (NESB) Higher Degrees Research (HDR) students. The outcomes of this research made a significant contribution to the academic standards, assessment practices, and reporting aspects of higher education which is a major priority projects program of the Australian Learning and Teaching Council (ALTC), by improving assessment practices throughout the sector, including investigation of the feasibility of a national portfolio assessment. For his excellent contribution to engineering education, Prof. Yarlagadda was elected as "Editor" by Association of Engineering Education in South East Asia and the Pacific. Through his involvement in the journal, he effectively contributed to excellent teaching practice for student learning and introduced several innovative teaching assessment techniques in Asia-Pacific region. In addition, he was elected as Chair Person, Asia-Pacific Conference of Engineering Management Educators 2002 to lead the educator's team in the Asia-Pacific Region; Chair Person of ACEME (Engineering Management Educators Conference) 2004 conference and Global Congress on Manufacturing and Management, to be held in December 2004.

\section{Community leadership and contributions to society}

Prof. Yarlagadda has provided eminent services to society over the past three decades. Prof. Yarlagadda has taken a number of community leadership positions in various Queensland-based community organisations during the 


\section{Advanced Materials Letters www.vbripress.com/aml}

past 15 years. Some of the offices that he held during past 10 years are; Vice-President and President of The Australia India Society Inc. (during 2004-2014), Vice President and President of Federation of Indian Communities of Queensland (FICQ 2010-2014) (Fig. 2(B) and Fig. 2(D), Vice President, Vedanta Centres of Queensland (2005present) Chair Person, Science, Technology and Innovation council Global Organisation for People of Indian Origin (GOPIO) (2016-present), and a number of other community organisations such as Queensland Telugu Association Inc, and so on. Through the above-mentioned roles, Prof. Yarlagadda established collaborative links and partnership between Queensland and Indian community. In addition, he has taken leadership role in establishing Tri Sister City Relationship between Brisbane, Australia; Hyderabad, India; and Ipswich, Australia. Prof. Yarlagadda's effort in establishing this tri-sister city relationship helped in attracting more than \$6 Billion investment from Indian companies such as Adani Mining, GVK Resources, Tata Steel, Jindal Steel, and companies from a number of other industries.

Prof. Yarlagadda is the Founding chairperson of University Cultural Diversity Committee at QUT. This committee provides advice on policies and programs which increase respect for cultural diversity at QUT. In this role, Prof. Yarlagadda initiated and promoted a number of support systems for number of students from low Socio-economical (SES) background, from Aboriginal and Torres Strait islander students (ATSI), ethnic and nonEnglish speaking background (NESB), and other disadvantaged students (Asylum students). These initiatives greatly helped to main Queensland school leavers and resulted in better opportunities and good quality of education for the above group of students and matured age students. Prof. Yarlagadda led a community-based research project to understand issues of the culturally and Linguistically Diverse (CALD) group to undertake their higher degree studies in Queensland University Outcomes of this project were implemented through Office of Learning and Teaching, Canberra, and a number of other participating universities in Queensland. Additionally, Prof. Yarlagadda also worked very closely with ARCBS, World vision, Qld., Diabetic society, and a number of organizations which take genuine interest in Queensland community.

Prof. Yarlagadda always thinks about community welfare and serving wider community, in whatever way it is possible. With this in mind, he has worked with other like-minded people like Dr Ramana Panda, Mr. Robin Jaggessar, and others. He established a trust named, Australia India House Charitable Foundation with an intention to serve and support people from low socioeconomic background in Australia. He works with a number of community organisations such as GOPIO, FICQ, Vedanta Centre of Queensland, universities, institutions, and other voluntary and charity organisations to support the basic needs of international students in difficult times. AIHCF closely works with student communities and other community organisations to understand their needs and support in the best possible way. As the Chairman of AIHCF foundation, Prof. Yarlagadda has taken a very active role in supporting a number of international students and other minority communities during the COVID-19 period, as it significantly impacted most of the communities around the world.

\section{Awards and recognition for his scientific contributions}

Because of his excellence in research, education, and community service, Prof. Yarlagadda has received several national and international honours and awards in his career. Some of them are: QUT Outstanding Academic Contribution Award in Research and Scholarship, for contribution to university mission and goals in research and scholarship, 2001; QUT Equity Award for outstanding efforts in supporting QUT's equity objectives and promotion of good practice and innovation in implementing equity within the university, 2001; Innovation in BEE Education award, as recognition to contribution in Teaching Innovation, 2002; Global Research Award (GCMM) as recognition to his contribution to Manufacturing Engineering Discipline, 2004; Fryderyk Staub Golden Owl Award (2007) from World Academy of Manufacturing and Materials, Poland, for outstanding contribution to the discipline of materials and manufacturing engineering in the international arena; Brisbane Times Multi cultural community award for his outstanding service and engagement with Queensland community 2008; Vice-Chancellor's Performance Award in 2008 for his research and leadership activities in Queensland University of Technology; Vice-Chancellor's Excellence Award for his research and leadership, 2009; Engineering Excellence Award (Fig. 3(A)) for his contribution of Airport of the future project (Queensland Winner and Australia Finalist), 2011 [13]; The Great Honorary Award from World Academy of Materials and Manufacturing Engineering in recognition of his lifetime achievement and outstanding contribution to scientific community and development of international scientific collaboration and partnership in the field of Materials and Manufacturing Engineering, 2012 (Fig. 3(B)); HDR Supervisory award in Faculty of Science and Engineering, QUT 2012.

Moreover, he received the Queensland International Fellowship to undertake research on permanent scaffolds in CMC \& VIT University, Vellore 2012; VAJRA Fellowship, Department of Science \& Technology, Government of India in 2018, 2020; and Prof. Yarlagadda was the first VAJRA professor commenced in India. One of the flagship awards and recognition that he received is the prestigious Medal of Order of Australia (Fig. 3(C)) from Governor General of Australia in recognition of his contributions to engineering profession and Indian Community in Queensland on Queens Birthday Honours. 2016 [14]. 


\section{Advanced Materials Letters www.vbripress.com/aml}

\section{Advancement of materials to global excellence}

International Association of Advanced Materials (IAAM) had the privilege to honour Prof. Prasad Yarlagadda with the Australian Advanced Materials Award 2020 during the $32^{\text {nd }}$ Assembly of Advanced Materials Congress in Sydney, Australia (Fig. 3(D)) [15]. Prof. Yarlagadda delivered the Australian Advanced Materials Award Lecture on the title: "Highly durable antiviral nanostructured surfaces for hospital applications". His opening talk addressed the contemporary health emergency of novel coronavirus (COVID-19) epidemic in China. Further, Prof. Yarlagadda talked about healthcare nanomaterials towards preventive control of viral infection. Healthcare Associated Infections (HAIs) are unknown killers that affect more people each year than Breast cancer and Prostate cancer combined. Therefore, transmission of bacteria and virus in hospitals should be reduced to decrease the number of HAIs. Prof. Yarlagadda and his team used bioinspired nano fabrication technique to nanotextured antimicrobial surfaces. Nanotextured surfaces were fabricated on Aluminium Alloy surfaces (Al 1200, Al 5052) by wet etching. He
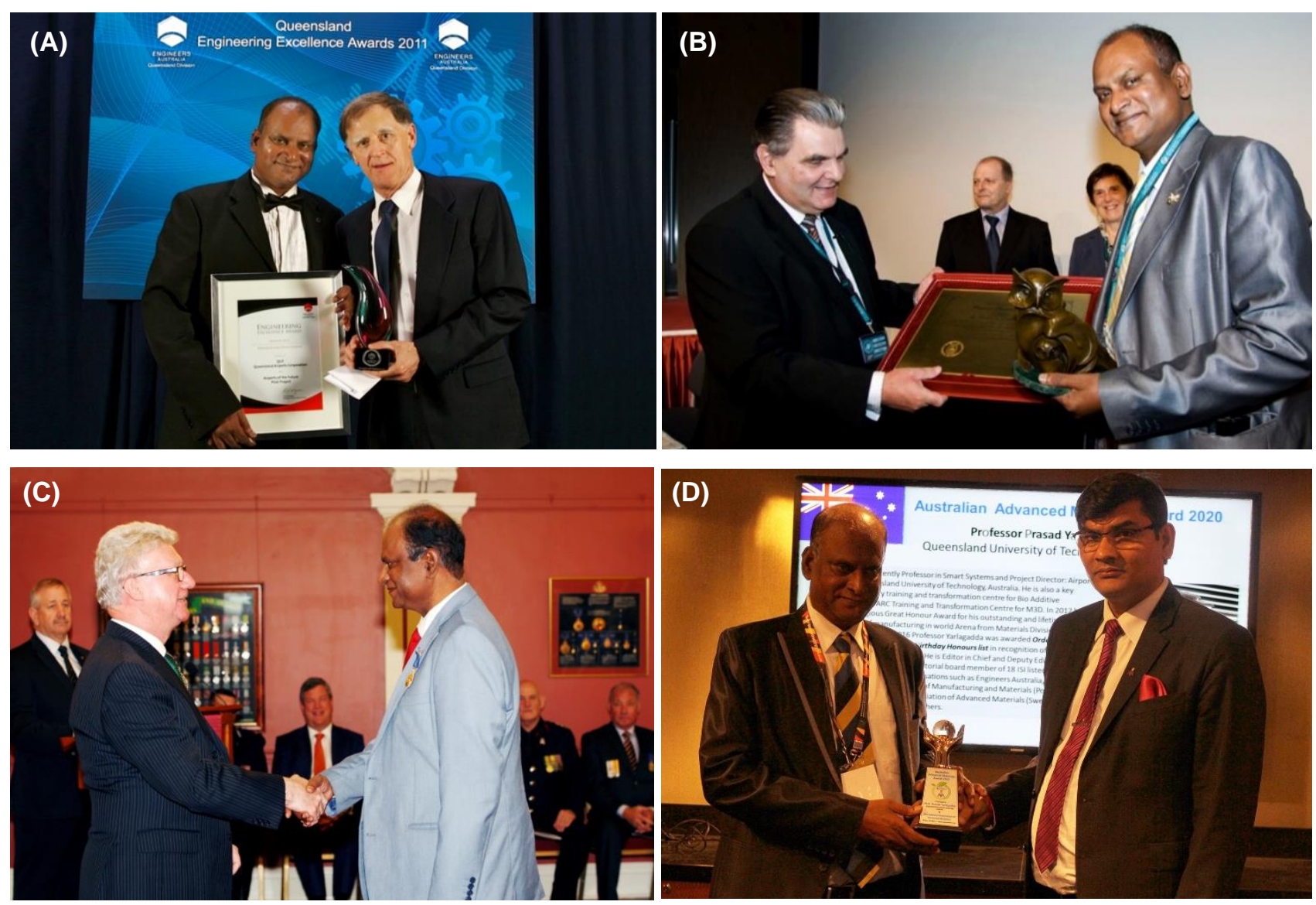

Fig. 3. Prof. Yarlagadda receiving Awards. (A) Engineering Excellence Award for his contribution to Airport of the future project (Queensland Winner and Australia Finalist), 2011; (B) The prestigious The Great Honour Award I 2012 from Prof. Leszek Dobrzanski, President, World Academy of Materials and Manufacturing Engineering in recognition of his life time achievement and outstanding contribution to scientific community and development of international scientific collaboration and partnership in the field of Materials and Manufacturing Engineering; (C) The prestigious Medal of Order of Australia from Governor General of Queensland in Recognition for contributions to engineering profession and Indian Community in Queensland on Queens Birthday Honours; (D) Australian Advanced Materials Award 2020 during the 32nd Assembly of Advanced Materials in Sydney, Australia from Prof. Ashutosh Tiwari (Secretary General and Director, IAAM). 


\section{Advanced Materials Letters www.vbripress.com/aml}

by adopting combination of both traditional and rapid prototype manufacturing techniques. In addition, Prof. Yarlagadda worked with famous researchers and institutes to develop the automated control technology for wielding processes for enhanced weld quality. In the subsequent years Prof. Yarlagadda and his team worked on increasing the microwave (alternative high energy technology) absorption for effective use in various manufacturing processes and product developments. Prof. Yarlagadda and his team also developed a Solar Energy Concentration System that can be used for manufacturing applications such as joining and ageing of polymers. Prof. Yarlagadda has also contributed in the areas of Product Data Modelling and Engineering Knowledge Management. He and his team attempted to design and develop a PDM-based system for the integration of critical business process, which are design, planning, and production, to achieve higher business performance. Initially, the PDM framework was extended to manage non-engineering data and support business activities of planning and production. Later, it was extended to integration-supported models including design model, routing planning model, and task model from the perspectives of information association and process automation.

Prof. Yarlagadda and his team worked on the Aviation and Airports Security and Safety. This research project started with a pilot study in 2007 to examine the efficient security and passenger flows and has since grown to a fiveyear multi-disciplinary program involving 33 research partners internationally. This research aimed to improve the safety, security, efficiency, and passenger experience within Australian airports by developing an integrated and adaptive complex systems approach for the design, management, and operation of airports. The ability to analyse, re-engineer, and manage such large-scale, multistakeholder, multi-jurisdictional, socio technical systems required significant advancement in both the understanding of 'complexity science' and its application [16]. His research contributions in the fields of high energy rate manufacturing, rapid prototype manufacturing, and rapid tooling lead to significant advancement in the discipline of manufacturing engineering. Prof. Yarlagadda's contribution to Rapid Tooling for Electro Discharge Machining, and Sheet Metal Forming and new Rapid Product Development techniques have been received very positively by industry partners such as Marco Engineering, EGR Plastics, and some of the local manufacturing companies such as Rover Mowers, Marky Industries, Mac trucks, and QMI. In addition, his recent contributions in aviation and airports received international recognition and attracted huge amount of research funding and interest of number of international and Australian agencies. As a result of his contributions to the field of manufacturing engineering, he was invited by several universities in USA, UK, South Korea, and other Asian countries to present invited papers, deliver lectures in seminars, and to develop joint research proposals under various international collaborative schemes with their universities.

\section{Efforts for promotion of biomedical research}

In the early years of his research career, Prof. Yarlagadda started working on implementing the advanced manufacturing techniques to medical applications. Permanent Scaffolds for Tissue Engineering is one of his research areas. Prof. Yarlagadda and his team worked on a number of issues related to permanent scaffolds by using Titanium and its alloys for various tissue engineering applications [17]. The tissue integration of a biomaterial is a critical factor in determining how well the implant material commonly used in bone surgery or reconstruction is incorporated into the human body. The biocompatibility of a biomaterial is highly related to the behaviour of the cells in contact and the cell adhesion to its surface. The material that can be used varies with the application intended. Tissue Engineering is one such application demanding certain requirements to be met before it is applied. One of the applications in tissue engineering is the tissue scaffold, which provides either a permanent or temporary support to the damaged tissues/organ until the functionalities are restored. The use of a material and morphology that depends on various factors such as Osteoinduction, Osteoconduction, angiogenesis, growth rates of cells, and degradation rate of the material in case of temporary scaffolds [18]. Prof. Yarlagadda has extensive collaboration with several researchers from various international institutes such as Singapore Institute of Manufacturing Technology, Singapore Government Hospital, Bio Scaffold Pty. Ltd, etc. for the development of permanent scaffolds for tissue engineering. In addition to this, Prof. Yarlagadda worked for developing the permanent scaffolds for orthopaedic and fracture fixation models $[\mathbf{1 9 , 2 0}]$.

In the subsequent years, Prof. Yarlagadda and his team started working on surface modification for orthopaedic applications. Different techniques such as nanosphere lithography, hydrothermal synthesis, electron beam lithography, and wet etching were used to fabricate nanotextured surfaces. Inspired from nature, Prof. Yarlagadda and his team fabricated patterned array of titanium nanopillars using electron beam lithography by biomimicking the insect wings (Cicada and dragon fly) (Fig. 4(A)). Three different Australian species of cicadas (Psaltoda claripennis, Aleeta curvicosta and Palapsalta eyrei) were characterized for the nanoscale architecture of the wings by using helium ion microscopy (HIM), scanning electron microscopy, atomic force measurement (AFM), and transmission electron microscopy (TEM) [1,7]. The chemical nature of the nanopatterned substrates was investigated using Fourier transform infrared spectroscopy (FTIR) and X-ray photoelectron spectroscopy (XPS). As a proof of concept, patterned nanopillars of titanium have been fabricated using the electron beam lithography technique directly inspired by the cicada wing architecture. The titanium nanopillars were observed to damage the bacterial cells of $P$. aeruginosa in a manner like the cicada wing species and remain compatible to osteoblast cells. 


\section{Advanced Materials Letters www.vbripress.com/aml}
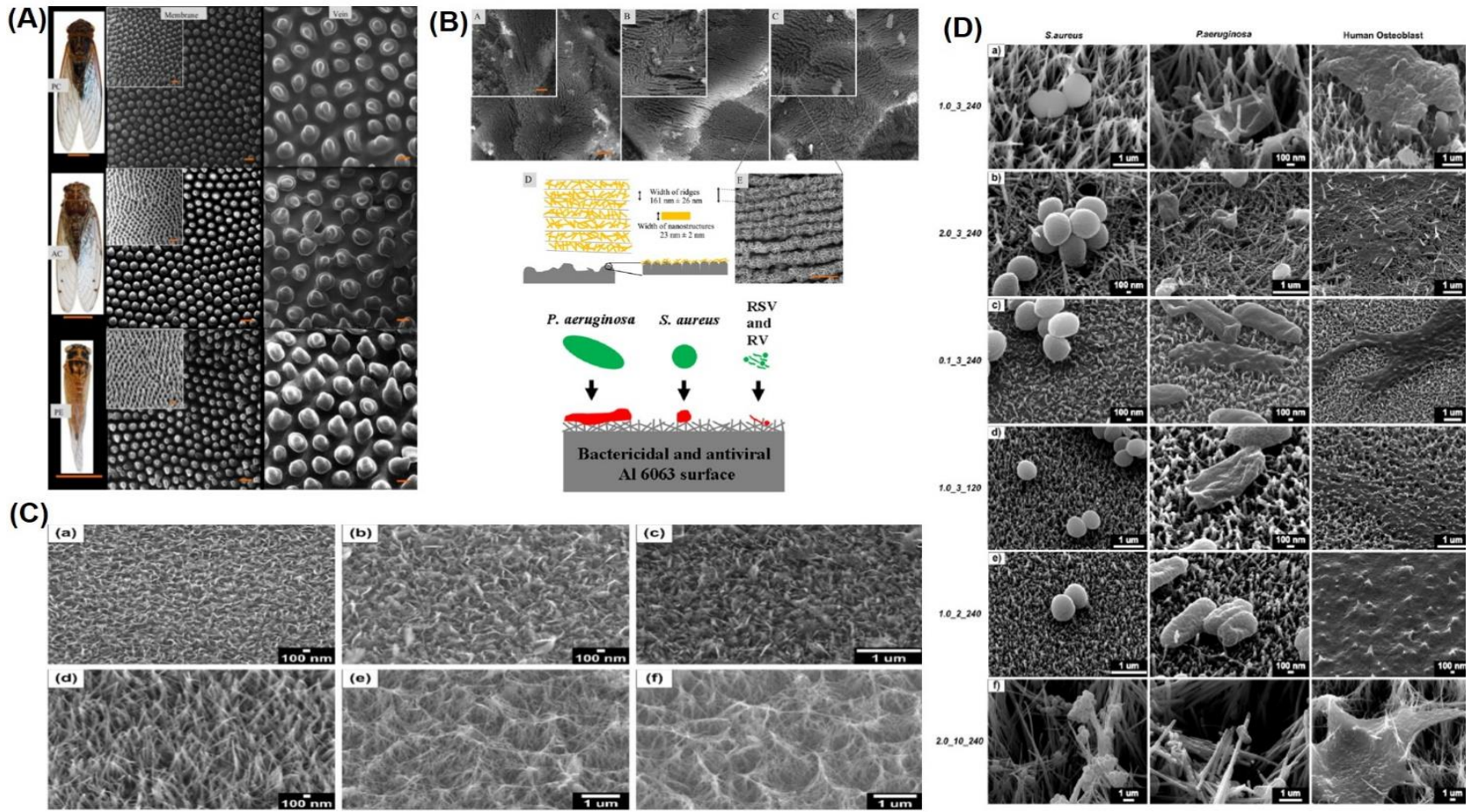

(C)
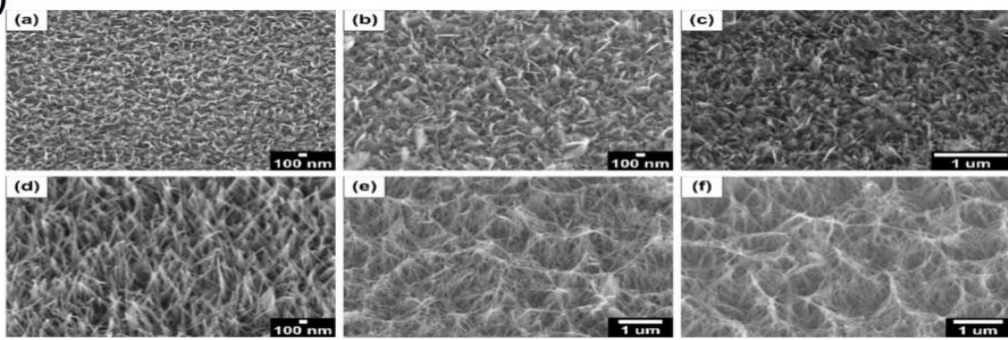

Fig. 4. (A) Photographs of the three cicada Psaltoda Claripennis (PC) Aleeta curvicosta (AC) and Palapsalta eyrei (PE) species (scale bars $=1 \mathrm{~cm})$ (left panel). Helium Ion microscopy (HIM) images of the corresponding wing membranes with insets depicting tilted ( $\left.30^{\circ}\right)$ view of the nanopillars on wings (middle panel). HIM images depicting surface morphology present on the veins of the same species (scale bars $=200 \mathrm{~nm})(\mathrm{right}$ panel). [Reproduced with permission from [7]]; (B) Surface morphology of surfaces fabricated at a $\mathrm{NaOH}$ concentration of (a) $0.10 \mathrm{M}$ (b) $0.25 \mathrm{M}$ (c) $0.50 \mathrm{M}$ (d) $1.00 \mathrm{M}$ (e) $1.50 \mathrm{M}$ (f) $2.00 \mathrm{M}$ ). [Reproduced with permission from [4]]; (C) Graphical representation and Scanning electron microscopy images of (A) 0.5, (B) 1, and (C) $3 \mathrm{~h}$ etched Al 6063 samples (scale bars $=2 \mu \mathrm{m}$, inset scale bars $=1 \mu \mathrm{m}$ ). (D) Schematic representations of the etched samples at higher (top) and lower (bottom) magnification. (E) SEM of the $3 \mathrm{~h}$ etched surface at higher magnification revealing the presence of random nanostructures (scale bar $=500 \mathrm{~nm}$ ). [Reproduced with permission from [5]]; (D) S. aureus (left), P. aeruginosa (middle) and $24 \mathrm{~h}$ osteoblast (right) cells on (a) 1.0_3_240, (b) 2.0_3_240, (c) $0.1 \_3 \_240$, (d) $1.0 \_3 \_120$, (e) 1.0_1_240 and (f) 2.0_10_240. [Reproduced with permission from [3]].

Recently, his team investigated the Mechanical, bactericidal, and osteogenic behaviours of hydrothermally synthesised $\mathrm{TiO}_{2}$ nanowire arrays [2] by varying $\mathrm{NaOH}$ concentration, reaction time, and reaction temperature (Fig. 4(B)). It was found that high alkaline concentrations produced large nanowire mesh arrays, while short reaction time and low temperature produced comparatively smaller arrays. The highly dense morphology formed at higher $\mathrm{NaOH}$ concentrations resulted in high elastic modulus and hardness values, compared to surfaces produced at lower $\mathrm{NaOH}$ concentrations. Viability tests of the $\mathrm{TiO}_{2}$ nanowire array against gram-positive Staphylococcus aureus cells showed a bactericidal efficiency of $54 \%$ and $33 \%$ after 3 and $18 \mathrm{~h}$, respectively. Later, a thorough examination of the surface, mechanical and wettability properties of multifunctional hydrothermally synthesised nanostructured materials were found to be capable of killing bacteria whilst improving osteoblast metabolic rates, leading to improved osseointegration and antibacterial properties of orthopaedic implants (Fig. 4(C)) [3]. Further to this, the mechanical properties, surface morphology, and stability of the $\mathrm{TiO}_{2}$ surface as a function of $\mathrm{NaOH}$ concentration were observed. At $\mathrm{NaOH}$ concentrations below $1.50 \mathrm{M}$, individual pillar-like nanostructures with high Young's modulus were formed. When $\mathrm{NaOH}$ concentration was increased above $1.50 \mathrm{M}$, nanostructure tips fused together to form a large, interconnected mesh-like network. This mesh-like structure caused a reduction in the Young's modulus and hardness of the titanium dioxide surface. It was also observed that the mechanical properties of the $\mathrm{TiO}_{2}$ remained constant over a 6-month period, indicating stability of the nanostructures [4].

More recently, his group focused on Antiviral and Antibacterial Nanostructured Surfaces with excellent mechanical properties for Hospital Applications [5]. The rise of bacterial and viral infections, including the recent outbreak of coronavirus, increased the urgency and requirement for novel antimicrobial strategies. To solve this problem and inspired by insect wing architecture, Prof. Yarlagadda, and his team, fabricated nanoscale features on aluminium alloy 6063 surfaces using a simple sodium hydroxide based wet-etching process (Fig. 4(D)). The surfaces were characterized using scanning electron microscopy, energy-dispersive X-ray spectroscopy, contact angle goniometry, nanoindentation, and atomic force microscopy. Strains of the Gram-negative bacteria Pseudomonas aeruginosa and the Gram-positive bacteria Staphylococcus aureus were used to evaluate the bacterial attachment behaviour. Further to this, for the first time, common respiratory viruses, respiratory syncytial virus 


\section{Advanced Materials Letters www.vbripress.com/aml}

(RSV), and rhinovirus (RV) were investigated for antiviral activity on nanostructured surfaces. The group found that the etched $\mathrm{Al}$ surfaces were hydrophilic, and the nanoscale roughness enhanced with the etching time (Rrms ranging from 69.9 to $995 \mathrm{~nm}$ ). The nanostructured surfaces were able to lyse $87 \%$ of the attached S. aureus and $92 \%$ of the attached P. aeruginosa bacterial cells. The recovery of infectious RSV was also reduced significantly within $2 \mathrm{~h}$ of exposure to the nanostructured surfaces compared to the smooth Al control surfaces. There was a 3-4 log 10 reduction in the viability counts of rhinovirus after $24 \mathrm{~h}$ on the nanostructured surfaces. The nanostructured surfaces exhibited excellent durability as the surfaces sustained 1000 cycles of $2000 \mu \mathrm{N}$ load without any damage. This is the first report that has shown the combined antibacterial and antiviral property of the nanostructured surface with excellent nanomechanical properties that could be potentially significant for use in hospital environments to stop the spread of infections arising from physical surfaces. To reduce healthcare associated infections, such kinds of bactericidal and antiviral activity on superior aluminium alloy surfaces could bring avant-garde transformation. ACS Biomaterials Science \& Engineering and News-Medical released a report to media highlighting the findings of this innovative research that can be extended to surfaces in other public areas, such as cruise ships, planes, and airports $[\mathbf{8 , 1 0}]$. Prof. Yarlagadda and his team are now studying the effects of their nano-textured surfaces on the novel coronavirus.

Prof. Yarlagadda's contribution to the discipline of manufacturing engineering, in particular broad area of additive biomanufacturing for medical devices manufacturing, is well recognised. He has contributed extensively as an academician, global researcher, scientist, professional, and community leader to the engineering community by developing various novel algorithms and processes for different engineering applications. Prof. Yarlagadda has dedicated majority of his life (36 years) to improvement of science and technology and its application to enhance the quality of human life, in specific aged population. In spite of number of opportunities to take administrative roles in Australian higher education sector, he committed to sticking to teaching and research as he enjoyed his profession and his interactions with young brains rather than spending time in administration. He prefers to spend his valuable time in training and nurturing young scientists and transforming young brains into intellectual and useful talent of society, which can further build the future world. International Association of Advanced Materials feels very honoured and privileged to confer upon Prof. Prasad Yarlagadda the title of 'Researcher of the Year' for his lifetime contributions and distinguished service to the field of advanced manufacturing and materials engineering. India News TV is recently published a video to tribute the efforts of Researcher of the year Prof. Prasad towards developing anti-viral and antipathogenic surfaces for various biomedical and engineering applications [21].
We heartily congratulate Prof. Prasad KDV Yarlagadda for being recognised as 'Advanced Materials Researcher of the year 2020'.

\section{References}

1. Hasan, J.; Roy, A.; Chatterjee, K.; Yarlagadda, PKDV.; ACS Biomater. Sci. Eng., 2019, 5, 3139.

2. Jaggessar, A.; Mathew, A.; Wang, H.; Tesfamichael, T.; Yan, C.; Yarlagadda, PKDV; J. Mech. Behav. Biomed. Mater., 2018, 80, 311.

3. Jaggessar, A.; Mathew, A.; Tesfamichael, T.; Wang, H.; Yan, C.; Yarlagadda, PKDV; Molecules, 2019, 24, 1201.

4. Jaggessar, A.; Tesfamicheal, T.; Wang, H.; Yan, C.; Yarlagadda, PKDV; Procedia Manuf., 2019, 30, 373.

5. Hasan, J.; Xu, Y.; Yarlagadda, T.; Schuetz, M.; Spann, K.; Yarlagadda, PKDV; ACS Biomater. Sci. Eng., 2020, 6, 3608.

6. "QUT researchers working on nano technology to contain COVID19 spread", viewed 03 November 2020 ,

<https://issuu.com/indiannewsqueensland/docs/inq_may_2020_vol_3_issue_8/s/10499790>

7. Shahali, H.; Hasan, J.; Mathews, A.; Wang, H.; Yan, C.; Tesfamichael, T.; Yarlagadda, PKDV; J. Mater. Chem. B, 2019, 7, 1300.

8. "New antiviral, antibacterial surface could reduce spread of infections in hospitals" viewed 03 November 2020, <https://www.acs.org/content/acs/en/pressroom/presspacs/2020/acs -presspac-may-27-2020/new-antiviral-antibacterial-surface-couldreduce-spread-of-infections-in-hospitals.html>.

9. "COVID-19 Prevention: Australian scientist developing new nanostructured materials whose surfaces can reduce spread of infection in hospitals and public areas", viewed 03 November 2020, $<$ https://www.thailandmedical.news/news/covid-19-preventionaustralian-scientists-developing-new-nanostructured-materialswhose-surfaces-can-reduce-spread-of-infection-in-hospitals-andpublish>.

10. "Novel antiviral, antibacterial surface can reduce hospital-acquired infections", viewed 03 November 2020, <https://www.newsmedical.net/news/20200527/Novel-antiviral-antibacterial-surfacecan-reduce-hospital-acquired-infections.aspx.>

11. Hasan, J.; Pyke, A.; Nair, N.; Yarlagadda, T.; Will, G.; Spann, K.; Yarlagadda, PKDV; ACS Biomater. Sci. Eng., 2020, 6, 4858.

12. "QUT scopes the world's airports of the future", viewed 03 November 2020, <https://www.businessacumen.biz/news-aviation/ 1191-qut-scopes-the-world-s-airports-of-the-future.>

13. "Queensland 'Airports of the Future' pilot project wins engineering award", viewed 03 November 2020 ,

<https://www.qut.edu.au/news?news-id=37466.>

14. "Medal (OAM) of the order of Australia in the general division" viewed 03 November 2020,

<http://old.gg.gov.au/sites/default/files/files/honours/qb/qb2016/nS _29ods1A/Media\%20Notes\%20-\%200AM\%20(S-Z).pdf>

15. "Australian Advanced Materials Award 2020" viewed 03 November $2020<\mathrm{https}: / / \mathrm{www}$.iaamonline.org/australian-advanced-materialsaward-2020.>

16. Farr, A.C.; Kleinschmidt, T.; Johnson, S.; Yarlagadda, PKDV; Mengersen, K.J.T.; Transport, 2014, 29, 90.

17. Sreejith, P.; Yarlagadda, PKDV; Aust. J. Mech. Eng,, 2009, 7, 77.

18. Veerachamy, S.; Yarlagadda, T.; Manivasagam, G.; Yarlagadda, PKDV; Proc. Inst. Mech. Eng., Part H, 2014, 228, 1083.

19. Harith, H.; Malekani, J.; Schmutz, B.; Schuetz, M.; Yarlagadda, PKDV; J. Biomimetics, Biomater. Biomed. Eng., 2013, 18, 1.

20. Schmutz, B.; Amarathunga, J.; Kmiec, S.; Yarlagadda, PKDV; Schuetz, M.; J. Orthop. Surg. Res., 2016, 11, 1.

21. "Researcher of the year | Tribute to Professor Prasad Yarlagadda | QUT | Advance Materials antiviral", online video, accessed on 07 November 2020.

<https://www.youtube.com/watch?v=HJB146Z8PJg>. 